\title{
Importance of bitewing radiographs for the early detection of interproximal carious lesions and the impact on healthcare expenditure in Japan
}

\author{
Peter Grieco $^{1}$, Ashiana Jivraj ${ }^{2}$, John Da Silva ${ }^{1}$, Yukinori Kuwajima ${ }^{3}$, Yoshiki Ishida ${ }^{4}$, Kaho Ogawa ${ }^{3}$, \\ Hiroe Ohyama ${ }^{1}$, Shigemi Ishikawa-Nagai ${ }^{5}{ }^{\wedge}$
}

${ }^{1}$ Department of Restorative Dentistry and Biomaterial Sciences, Harvard School of Dental Medicine, Boston, MA, USA; ${ }^{2}$ Harvard School of Dental Medicine, Boston, MA, USA; ${ }^{3}$ Department of Developmental Oral Health Science, Iwate Medical University, School of Dental Medicine, Iwate, Japan; ${ }^{4}$ Department of Dental Materials Science, School of Life Dentistry at Tokyo, The Nippon Dental University, Tokyo, Japan; ${ }^{5}$ Department of Oral Medicine, Infection and Immunity, Harvard School of Dental Medicine, Boston, MA, USA

Contributions: (I) Conception and design: P Grieco, J Da Silva, S Ishikawa-Nagai; (II) Administrative support: P Grieco, Y Kuwajima, Y Ishida, H Ohyama, S Ishikawa-Nagai; (III) Provision of study materials or patients: S Ishikawa-Nagai; (IV) Collection and assembly of data: Y Kuwajima, Y Ishida, K Ogawa, S Ishikawa-Nagai; (V) Data analysis and interpretation: All authors; (VI) Manuscript writing: All authors; (VII) Final approval of manuscript: All authors.

Correspondence to: Shigemi Ishikawa-Nagai, DMD, PhD, MSD. Associate Professor, Department of Oral Medicine, Infection and Immunity, Harvard School of Dental Medicine, 188 Longwood Avenue, Boston, MA 02115, USA. Email: shigemi_nagai@hsdm.harvard.edu.

Background: Globally, the direct cost of dental caries is approximately \$298B yearly, consuming $5-10 \%$ of national healthcare budgets. Bitewing radiographs (BWR) are the standard method of diagnosing interproximal dental caries. In Japan, bitewing radiographs are rarely used. This retrospective observational study was conducted to measure the potential economic impact of carious lesions left undiagnosed and untreated due to this omission of bitewing radiographs.

Methods: The total number of existing carious lesions, the number of undiagnosed lesions, and costs of treating these lesions were calculated from the national database of Ministry of Health, Labor and Wellness in Japan between June 2013 and 2017. The number of affected teeth was estimated using prevalence data and undiagnosed lesions were estimated. The expense associated with treating progressed lesions was calculated using the standard Japanese fee structure. BWR trends were assessed, and analyses were performed to understand the differences between states and populations over time.

Results: The average number of BWR taken monthly per office was $48.3 \pm 1.1$ (average \pm SD). It was calculated that an average of 6,429,155 lesions went undiagnosed per month, 93.5 teeth per practice, and 1.6 teeth per patient. The cost of treating lesions that went undiagnosed and then progressed into more invasive restorations was estimated to be between $\$ 57 \mathrm{M}-\$ 218 \mathrm{M}$ more (difference between $\mathrm{NaF}$ varnish and class II restorations), and \$150M-\$443M more (difference between Class II restoration and crown or crown with RCT).

Conclusions: BWRs are crucial in diagnosing a significant number of carious lesions. There is considerable impact on health and cost to the national health system due to undiagnosed lesions. Practitioners need to be educated on reading and understanding BWR, and policy should be changed to cover BWR.

Keywords: Bitewings; cariology; prevention; health expenditures

Submitted Apr 28, 2021. Accepted for publication Oct 12, 2021.

doi: 10.21037/atm-21-2197

View this article at: https://dx.doi.org/10.21037/atm-21-2197

^ ORCID: 0000-0001-6364-6552. 


\section{Introduction}

Dental caries is a costly disease to treat, consuming $5-10 \%$ of healthcare budgets in industrialized countries. It is one of the 10 most frequent global causes of death, and is among the most prevalent causes of hospitalization of children in some high-income countries $(1,2)$. In 2015-2016, the prevalence of caries (untreated and treated) in American children and adolescents aged 2-19 years was $45.8 \%$, while the prevalence of untreated caries in the same population was $13.0 \%$ (3). Caries prevalence was lowest in youth aged 2-5 years compared with those aged 6-11 and 12-19 for total caries experience $(21.4 \%, 50.5 \%, 53.8 \%)$ as well as untreated caries $(8.8 \%, 15.3 \%, 13.4 \%)(3)$. Untreated caries prevalence increased from 2011-2012 (16.1\%) to 20132014 (18.0\%), and then decreased in 2015-2016 (13.0\%). Understanding the economic burden of oral diseases is also important to improve the societal approach towards preventing and addressing oral diseases. The World Health Organization, in 2010, indicated that direct treatment costs due to dental diseases worldwide were $\$ 298 \mathrm{~B}$, corresponding to $4.6 \%$ of global health expenditure (\$6.5 trillion in 2010) $(2,4)$. Although largely preventable, dental caries is the most common chronic disease in the US: $91 \%$ of Americans over 20 have experienced caries at some point in their lives (5).

Although there have been many developments in the methods of caries detection, including transillumination $(6,7)$, quantitative light fluorescence (8), and laser fluorescence (9-11), radiographs are still the primary diagnostic tool for the detection of interproximal dental caries (12). Accurate reading of radiographs is paramount for caries detection (13). Bitewing radiographs (BWR) have been shown to be superior to periapical or panoramic radiographs for diagnosing interproximal carious lesions, particularly in the early stages of caries formation (14). The care model for dental caries management is moving toward non-operative/preventive care (15). The World Dental Federation made a statement in support of using Minimal Intervention Dentistry (MID) as the contemporary way to manage caries (16). In order to make minimally invasive treatment possible, dental caries needs to be diagnosed in the earliest stages (17). Higher sensitivity is required for early detection of dental caries, such as in enamel. BWR show significantly better sensitivity than periapical radiographs for all levels of caries progression (BWR: 94.5 for dentin caries, 90.43-82.7 for enamel caries, periapical: 69.7 for dentin caries, 39.01-56.2 for enamel caries), although there was no significant difference on specificity (18).
MID is a viable treatment option for enamel caries, in that false positives (caries misdiagnosed as being present when it is actually not) would not lead to treatments that irreversibly cause tooth structure to be removed from a healthy tooth (18). Previous studies have shown that BWR offer a significant advantage over periapical radiographs in the diagnosis of early stages of interproximal caries (IC) (18). BWR serve as an important tool in the accurate diagnosis of early stage lesions and is thus one of the most essential services that need be included in preventative and early interventional dental care plans (19).

In the United States, BWR is the standard of care for diagnosing interproximal carious lesions and is taught in all dental schools (12). However, the implementation and insurance coverage of BWR varies among countries; for instance, the Japanese universal health care system does not cover BWR for diagnostic purposes, likewise in other nations with universal healthcare coverage (20).

In this retrospective observational study, we investigated the effect of not taking BWR on the potential underdiagnosis of IC and calculated the potential economic impact. The Japanese universal healthcare system was selected because medical and dental care are recorded together. For dentistry, insurance covers most dental services except for preventative care, aesthetic restorations, dental implants, and orthodontics, among others. In 2011, the Japanese Ministry of Health, Labor and Welfare established that third parties can access the UHCS database under ${ }^{1}$ government guidelines. First, the approximate number of teeth in which IC was left undiagnosed when BWR are not taken was calculated. Second, the potential cost of dental treatments that would have been performed if BWR are taken was determined. Last, the excess financial burden due to allowing lesions to progress rather than intervene with early diagnosis and treatment was calculated. It is hypothesized that there is a large cost associated with not treating these undiagnosed carious lesions, missed by not taking BWR, in addition to the potential missed opportunities to treat or monitor caries in their incipient or dentinal phases, allowing progression to larger, more complicated lesions. We present the following article in accordance with the STROBE reporting checklist (available at https://dx.doi.org/10.21037/atm-21-2197).

\section{Methods}

Access to the national dataset of medical and dental reimbursements from 2013 to 2017 from the Japanese 


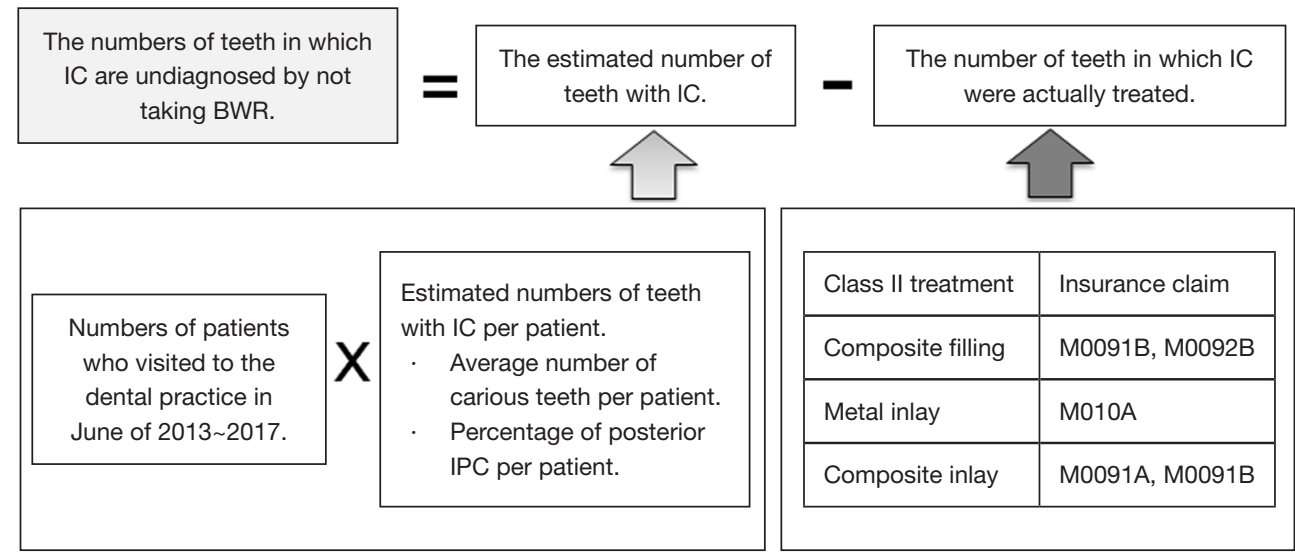

Figure 1 The formula to calculate the numbers of teeth in which interproximal caries (IC) remain undiagnosed by not taking bitewing radiographs (BWR).

universal healthcare system (UHCS) was obtained. This study was approved by Japan's Ministry of Health, Labor and Welfare (JMHLW) in 2018 and the Institutional Review Board of Iwate Medical University Japan (IMU_01301) and conducted in accordance with the Declaration of Helsinki (as revised in 2013).

\section{Frequency of BWR}

The number of BWR per practice monthly (BWRPPM) in each of 47 states was assessed and the trends were graphed. The frequency of BWR was also compared to panoramic and periapical radiography using the public annual report by JMHLW.

\section{Statistical analysis}

One-way ANOVA analyses were performed to identify significant differences on the numbers of BWR per practice between years. The association between BWRPPM and monthly dental cost per person per month (DCPP) was analyzed using Spearman's correlation coefficient.

\section{The number of teeth in which interproximal caries (IC) is left undiagnosed by not taking BWR}

The formula to estimate the number of teeth in which IC remains undiagnosed due to not implementing BWR was created (Figure 1). Undiagnosed IC was defined as the difference between the estimated number of affected and treated teeth with IC. The estimated IC was calculated by multiplying the total number of patients by the average number of carious teeth per patient and by the percentage of those located in the interproximal posterior areas. White's estimation of carious teeth as well as the percentage of posterior caries was applied (21). The average number of patients visiting the dental practice monthly was calculated from the database of JMHLW between 2013 and 2017 (22).

To evaluate the cost of treatment, the expected depth of the caries treated was investigated, which determines the type of treatment needed. The depths of carious lesions were classified per White's article as Outer Enamel (14\%), Inner Enamel (27\%), Shallow Dentin (24\%), Deep Dentin (19\%), and Recurrent (19\%). The number of teeth undiagnosed was then divided into subgroups based on these proportions (21). Treatment modalities were then identified: lesions in enamel would be treated by fluoride varnish, and lesions into dentin would be treated with composite fillings or metal inlays. In the case that caries into dentin remained undiagnosed and progressed into a larger lesion, recommended treatment would be a full coverage restoration with or without root canal treatment (RCT). The cost of these treatments was extrapolated from the national registry (22).

The number of teeth with caries treated was calculated as the sum of the number of class II restorations billed, such as, composite fillings, metal inlays, and composite inlays, denoted by codes M0091B, M0092B, M0101A, M0091A, and M0091B from the JMHLW data (22). The difference between these two values was the estimated number of undiagnosed carious teeth in the Japanese healthcare system. 


\begin{tabular}{|c|c|c|c|c|}
\hline $\begin{array}{c}\text { Initial } \\
\text { diagnosis }\end{array}$ & BTW & $\begin{array}{l}\text { Recommended treatment } \\
\text { if IC was not undiagnosed }\end{array}$ & $\begin{array}{c}\text { Recommended treatment for IC at the level } \\
\text { of progression }\end{array}$ & $\begin{array}{c}\text { Projected } \\
\text { extra } \\
\text { expenditure }\end{array}$ \\
\hline \multirow[t]{2}{*}{$\begin{array}{c}\text { Enamel } \\
\text { caries }\end{array}$} & Taken & $\begin{array}{cc}\text { Extension of lesion } \\
\cdot \quad & \text { Outer enamel } \\
\cdot & \text { Inner enamel }\end{array}$ & ended E1 & \multirow{2}{*}{ E2-E1 } \\
\hline & $\begin{array}{l}\text { Not } \\
\text { taken }\end{array}$ & Progression & $\begin{array}{l}\text { storations recommended } \\
\text { iposite filling } \\
\text { al inlay } \\
\text { posite inlays }\end{array}$ & \\
\hline \multirow[t]{2}{*}{$\begin{array}{l}\text { Shallow } \\
\text { dentin } \\
\text { caries }\end{array}$} & Taken & $\begin{array}{cl}\text { Extension of lesion } \\
\cdot \quad \text { Shallow dentin } \\
\cdot \quad \text { Deep dentin } \\
\cdot \quad \text { Recurrent }\end{array}$ & ommended D1 & \multirow{2}{*}{ D2-D1 } \\
\hline & $\begin{array}{l}\text { Not } \\
\text { taken }\end{array}$ & Progression $>\begin{array}{c}\text { Larger } \\
\text { dentin } \\
\text { caries }\end{array}$ & $\begin{array}{l}\text { treatment recommended } \\
\text { wn } \\
\text { t canal treatment (RTC) }\end{array}$ & \\
\hline
\end{tabular}

Figure 2 The formula to calculate the projected extra expenditure of treatments required for the undiagnosed IC after caries progression. E1: The expenditure of preventive care recommended. E2 and D1: The expenditure of class II restorations recommended. D2: The expenditure of extensive treatment recommended.

\section{The projected extra expenditure of treatments required for the undiagnosed and progressed IC lesions}

The formula to calculate the projected extra expenditure of treatments required for the IC was created (Figure 2), and incorporates the varying recommended treatments indicated for different extents of IC. Recommended treatments of caries diagnosed via BWR are preventive care (fluoride varnish, promotion of oral hygiene) for caries only within enamel and class II restorations (composite fillings, metal inlays, and composite inlays) for caries extending into dentin (23). Undiagnosed lesions that are not treated may progress, eventually requiring extensive class II restorations, root canal treatments (after extension into the pulp), and full coverage restorations (when there is extensive tooth structure loss). White's method was utilized to calculate the number of teeth which could have IC in each of the extension level of lesions: outer enamel, inner enamel, shallow dentin, deep dentin, and recurrent caries (21). The aggregate cost of these treatments was then calculated based on Japan's government healthcare system fees. The difference in the cost of treating extended lesions due to undiagnosed IC (extended Class II restorations, root canal treatments, and crowns) and treating initial IC lesions was calculated.

\section{Results}

\section{Radiograph frequency}

From June 2013 through 2018, there were 4,029,234 total periapical radiographs and $1,347,665$ total panoramic radiographs (Figure 3). In comparison there were only 48,882 BWR acquired (Figure 3). There was an inconsistent number of radiographs taken across states with the highest states taking 110.3 BWR per month per practice (state 42), and the lowest taking $8.7 \mathrm{BWR}$ (state 44) (Figure 4).

The average of number of monthly BWR per office over the period evaluated ranged from 4.27-50.3 among the 47 states. There was no significant difference among the 6 years evaluated. Spearman's correlation coefficient between average number of BWRPPM and monthly DCPP from 2012-2017 was 0.337 with no significance $(\mathrm{P}=0.0203)$.

\section{Number of IC that could be missed by not taking BWR}

Utilizing the report by JMHLW, the average number of patients who visited a dental practice in the months of June between 2013 and 2017 was 4,044,173 (22). According to White et al., the average number of carious teeth per patient was 3.21 , and $79.7 \%$ of those teeth would be posterior interproximal caries (IC). Thus, there should be 


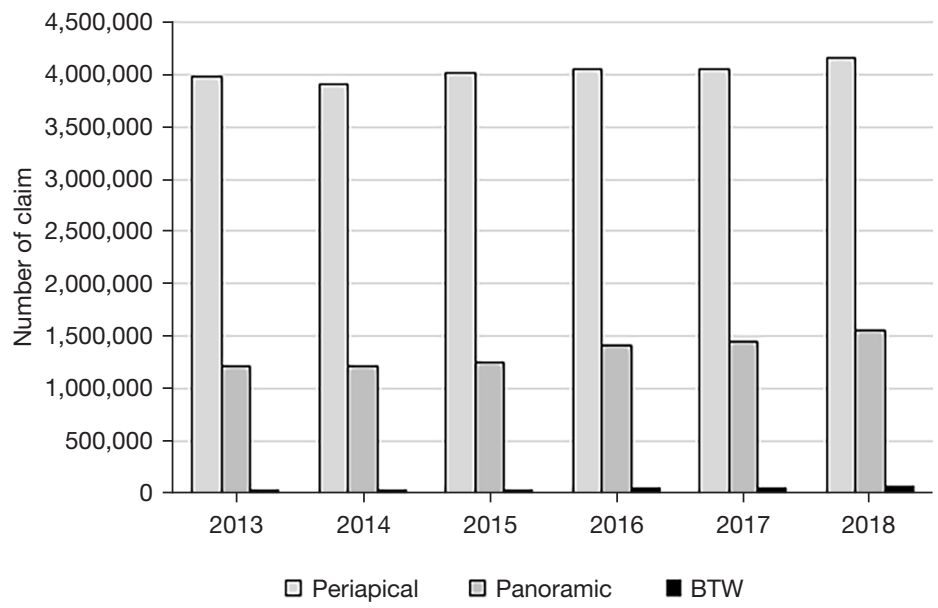

Figure 3 The total number of 3 types of radiographs taken in June 2013-2018 (published data by Japan's Ministry of Health, Labor and Welfare: JMHLW).

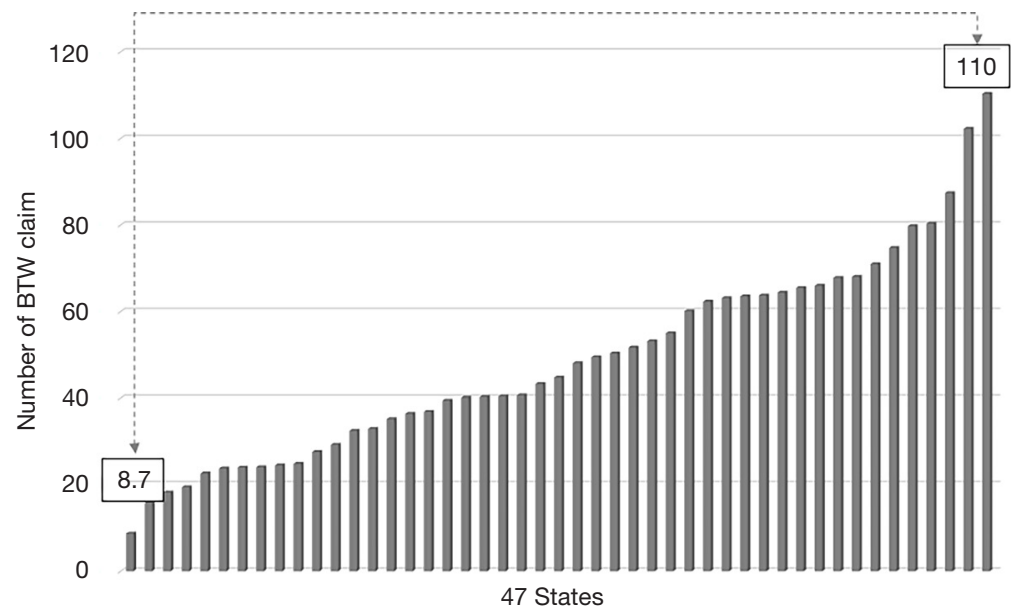

Figure 4 The average number of bitewing radiographs (BWR) taken per practice per month in each of 47 states in year 2017.

an estimated 2.5 carious posterior teeth per patient (21). Extrapolating this value, an estimated 10,344,994 carious teeth were expected to be observed and treated in those patients. However, using the national report, the total number of teeth treated (composite fillings, metal inlays, and composite inlays) was only $3.9 \mathrm{M}$ teeth (Table 1) (22). The difference in estimated and observed equals $6.4 \mathrm{M}$ teeth, indicating the untreated IC lesions. This equals 93.5 $( \pm 7.5)$ IC left undiagnosed per clinic per month.

Based on the estimated number of carious lesions left undiagnosed in the outer and inner enamel $(861,507+1,748,730)$, treatment with fluoride varnish would cost $\$ 308,216$ per year by self-pay as insurance doesn't cover preventive care. In the case that caries remained undiagnosed, and then progressed to requiring a class II restoration, the cost would be $\$ 57 \mathrm{M}-\$ 58 \mathrm{M}$ for class II composite restorations and \$191M-\$218M 191,568,334-\$218,122,361 for metallic inlays (Figure 5). For the total estimated undiagnosed shallow dentin caries $(1,562,285)$, the average cost of class II restorations would be $\$ 82 \mathrm{M}$ ( $\$ 42 \mathrm{M}$ if with a composite filling and $\$ 122 \mathrm{M}$ if with a metallic inlay). In the case that these undiagnosed carious lesions progressed and necessitated a full-coverage restoration, the calculated treatment costs would be $\$ 233 \mathrm{M}$ with a metal crown, or $\$ 400 \mathrm{M}$ with a CAD/CAM crown. These figures would increase to $\$ 358 \mathrm{M}$ and $\$ 525 \mathrm{M}$ 
Table 1 Average number of tooth with interproximal caries (IC) that could be undiagnosed per month per dental practice

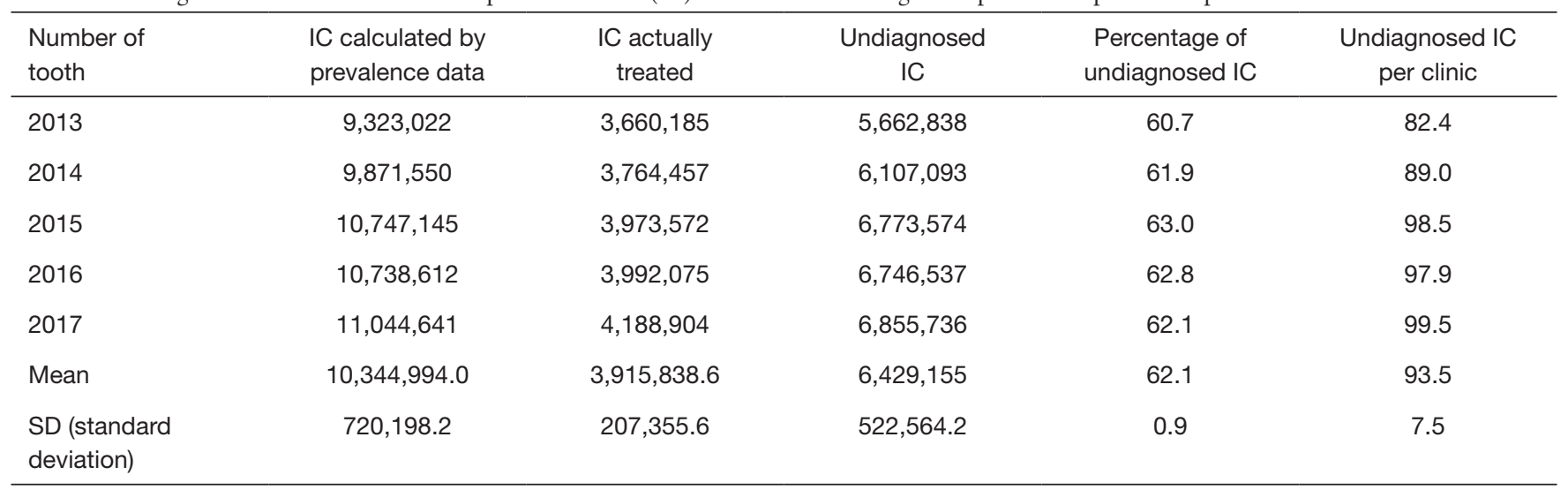
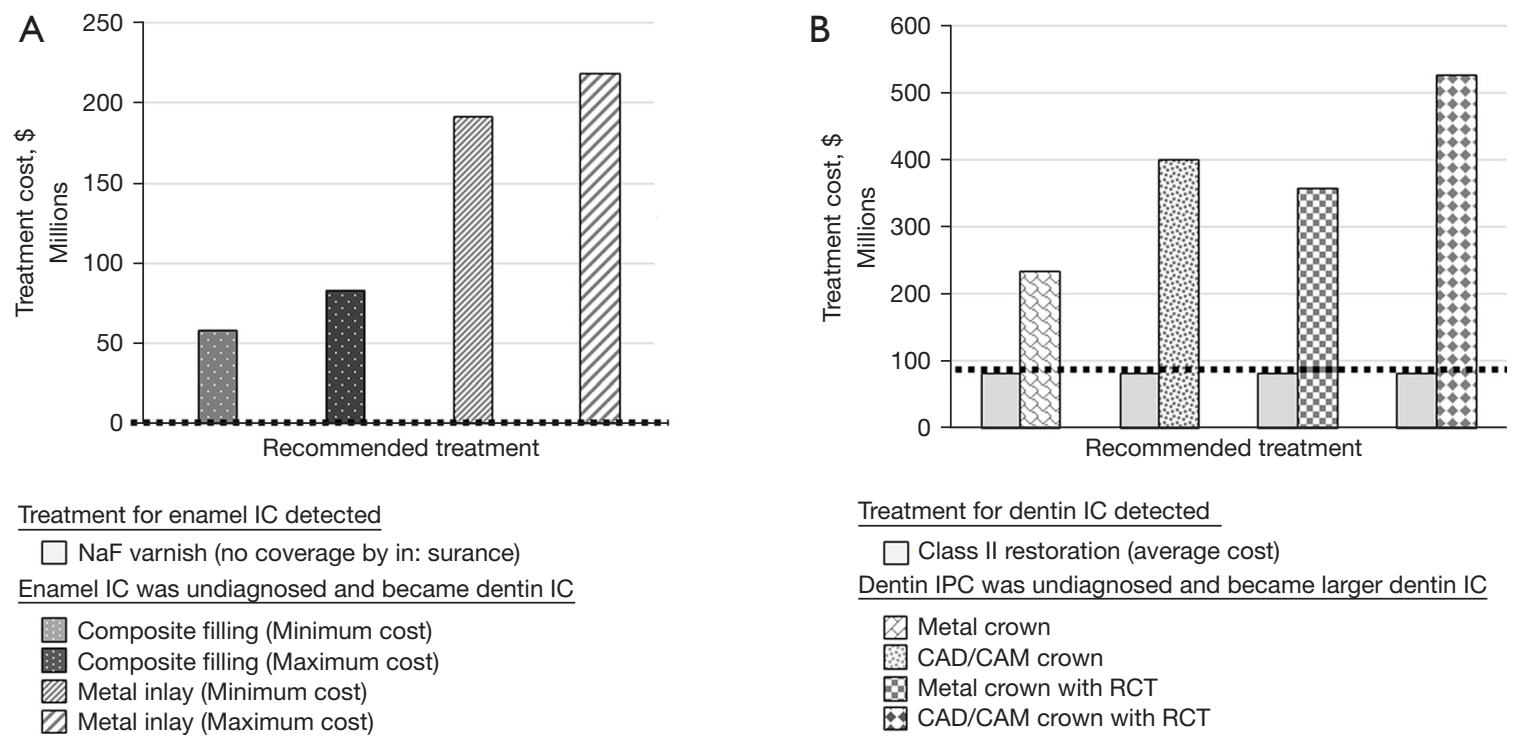

Figure 5 Average projected extra expenditure of treatments required for undiagnosed interproximal caries (IC). (A) Enamel caries, (B) Shallow dentin caries.

respectively, if the tooth required a RCT (Figure 5). If caries was diagnosed and treated with a class II restoration, \$150M-\$443M expenditure would be saved.

\section{Discussion}

These data represent a significant number of interproximal lesions, approximately 6,429,155 teeth per month, that have potentially gone undiagnosed due to a lack of BWR being taken. Because interproximal lesions are often not clinically visible, radiographs are required to detect these lesions (24). BWR are far more sensitive to caries detection of posterior interproximal lesions than panoramic radiographs (14). Lesions that can be seen on BWRs include both cavitated and non-cavitated lesions into the enamel and dentin (25). In Japan, the extra cost of treatment incurred by not diagnosing these lesions amounts to approximately $\$ 47 \mathrm{M}-\$ 1 \mathrm{~B}$ per year. Through early detection and prevention, more extensive and expensive treatments can be avoided (26). Simply calculating, if BWR were taken for all patients once a year, the cost of BWR (4 bitewings) would be $\$ 14 \mathrm{M}(1.5 \mathrm{E}+07)$, which is significantly less than the expected cost of progressed undiagnosed caries. It is, therefore, beneficial to the patient, the provider, and the national health care system to use 
BWRs to diagnose and prevent the progression of IC lesions.

Outside of Japan, BWRs are commonly used to diagnose interproximal lesions (12). The data indicated a large difference between the number of BWRs taken and periapical and panoramic radiographs. The potential reasons could be (I) Japanese UHCS don't cover BWRs for diagnostic purposes. (II) Panoramic radiographs are covered. The most common pattern for a new patient visit is taking a panoramic first and then taking a periapical for specific teeth that have problems diagnosed using a panoramic film and a clinical examination. (III) Taking BWRs in addition to the panoramic and periapical radiographs takes too much time and dentists prefer not to do so. (IV) Patients do not want to have BWRs that are not covered by insurance for diagnostic purposes. This article could help change this unique culture to make both dentists and patients understand the benefits of BWRs. By using strict criteria for defining the presence of lesions, despite a relatively high presence of false-negatives, there is much higher degree of specificity (24). The false-negative risk can be mitigated by taking BWRs with sufficient frequency to avoid missing lesions. In a high caries risk patient, it is recommended that bitewings be taken every $6-12$ months, whereas in a low caries risk patient, every $2-3$ years appears to be sufficient (27). The additional diagnostic yield of radiographs for IC is $204-336 \%$, indicating much higher effectiveness than just clinical examination (19). It is crucial to teach clinicians how to read bitewings. Developing a combination of clinical judgment as well as analytic prowess leads to increased diagnostic accuracy for students-intraining (28). Individuals who have been trained in systems without using BWRs as a diagnostic tool may need further education in order to be competent in reading radiographs. Although, transillumination may be an effective method of detecting carious lesions, this technology is not currently as widely used (7).

Once lesions are diagnosed, it is important to assign the proper treatment modality, based on lesion depth. In the enamel, lesions can be remineralized using fluoride to control disease progression (29). MID can protect teeth from secondary caries and fractures (17). Once the lesion extends into dentin, treatment with a restoration is recommended (23). Over the last 150 years, amalgam fillings were the primary modality for treating caries of the dentin, but in many countries, this has shifted to resin composite fillings due to aesthetics and the potential environmental impact of mercury (30). Generally, failure of a direct composite restoration occurs most frequently due to recurrent caries or restoration fracture (31). There is no significant difference observed between direct and indirect treatment modalities for posterior restorations, though further clinical research is recommended (32).

Limitations of this retrospective observational study include a dependence on estimates of existing carious lesions. Further, the estimated distribution of the extent of the lesions in this study ${ }^{2}$ uses prevalence data obtained from the United States and there may be differences in caries prevalence, location, or distribution between Japan and the US. The four recent studies reported following: (I) The prevalence of dental caries among adults aged 20-64 years (2011-2016) was $90 \%$, which is a slight decrease from $92 \%$ during 1999-2004. Among adults with caries, mean DFT was 7.4, lower than the estimate of 8.2 during 1999-2004. Mean DFT and FT both decreased by about one tooth overall (33), (II) The untreated caries decreased $12 \%$ that is reflecting one tooth decrease (8.2 to 7.4) in DFT (34), (III) Population DFT scores decreased over time in all countries examined (UK, USA and Sweden), except Japan (35), (IV) The Japanese Ministry of Health, Labor and Welfare report indicated that DFT in Japanese adults (age 25-65) is 12.0 in 2011-2016 and 12.9 in 1999-2004 (36), these numbers are greater than the US data. In case of 4-12\% decrease of caries prevalence, estimated expenditures would be $88-96 \%$ of present numbers calculated in Figure 5. Although the results still could be over or under-estimated due to the accuracy of the formula used, the results of this study could provide an important message to nations not using BWRs for routine examinations. Furthermore, progression of lesions in the enamel and false positives are concerns, for this reason, dentists should use BWR to monitor interproximal caries.

In addition, limitations also exist in predicting which treatment modality a dentist would select, the decision to treat or not to treat a lesion lies at the basis of clinical judgement and each dentist has a unique methodology for creating treatment plans. It is these differences that lead to the wide range of expenses possible to treat carious lesions.

Further research should focus on the additional diagnostic value of BWRs, such as quantifying bone loss and other periodontal diseases. One should study the costs of taking BWRs, to understand the differential between true cost of preventing disease and the sequelae of further disease. Furthermore, a prospective observational clinical study should be performed to monitor undiagnosed IC over time. Policy changes should be made to include diagnostic BWRs within national dental insurance in countries that currently 
do not include them, and to further increase the acceptance of BWRs. In addition, educating and incentivizing providers to use BWRs to diagnose and to prevent progression of IC will be crucial in preventing more compromised outcomes.

\section{Conclusions}

By not taking BWR, dentists may fail to diagnose many carious lesions. Not diagnosing these lesions precludes the opportunity to prevent caries progression and leads to significant subsequent expenditures for larger required invasive treatments. The oral health of the Japanese population may be compromised because of undiagnosed disease.

\section{Acknowledgments}

Funding: None.

\section{Footnote}

Reporting Checklist: The authors have completed the STROBE reporting checklist. Available at https://dx.doi. org/10.21037/atm-21-2197

Data Sharing Statement: Available at https://dx.doi. org/10.21037/atm-21-2197

Peer Review File: Available at https://dx.doi.org/10.21037/ atm-21-2197

Conflicts of Interest: All authors have completed the ICMJE uniform disclosure form (available at https://dx.doi. org/10.21037/atm-21-2197). The authors have no conflicts of interest to declare.

Ethical Statement: The authors are accountable for all aspects of the work in ensuring that questions related to the accuracy or integrity of any part of the work are appropriately investigated and resolved. This study was approved by Japan's Ministry of Health, Labor and Welfare (JMHLW) in 2018. This study was also approved by the Institutional Review Board of Iwate Medical University Japan (IMU_01301) and conducted in accordance with the Declaration of Helsinki (as revised in 2013).

Open Access Statement: This is an Open Access article distributed in accordance with the Creative Commons
Attribution-NonCommercial-NoDerivs 4.0 International License (CC BY-NC-ND 4.0), which permits the noncommercial replication and distribution of the article with the strict proviso that no changes or edits are made and the original work is properly cited (including links to both the formal publication through the relevant DOI and the license). See: https://creativecommons.org/licenses/by-nc-nd/4.0/.

\section{References}

1. WHO. Sugars and dental caries [cited 2021 March 23]. Available online: https://www.who.int/news-room/factsheets/detail/sugars-and-dental-caries.

2. Listl S, Galloway J, Mossey PA, et al. Global Economic Impact of Dental Diseases. J Dent Res 2015;94:1355-61.

3. Fleming E, Afful J. Prevalence of Total and Untreated Dental Caries Among Youth: United States, 2015-2016. NCHS Data Brief 2018;(307):1-8.

4. Spending on health: A global overview [cited 2021 March 23]. Available online: https://www.who.int/news-room/ fact-sheets/detail/spending-on-health-a-global-overview.

5. statement A. New CDC Statistics Show Need for Increased Access to Dental Care, with a Greater Emphasis on Preventing Disease [cited 2021 March 9]. Available online: https://www.ada.org/en/press-room/news-releases/2015archive/may/new-cdc-data-on-adult-cavities.

6. Schneiderman A, Elbaum M, Shultz T, et al. Assessment of dental caries with Digital Imaging Fiber-Optic TransIllumination (DIFOTI): in vitro study. Caries Res 1997;31:103-10.

7. Lara-Capi C, Cagetti MG, Lingström P, et al. Digital transillumination in caries detection versus radiographic and clinical methods: an in-vivo study. Dentomaxillofac Radiol 2017;46:20160417.

8. Heinrich-Weltzien R, Kühnisch J, van der Veen M, et al. Quantitative light-induced fluorescence (QLF)--a potential method for the dental practitioner. Quintessence Int 2003;34:181-8.

9. Bizhang $M$, Wollenweber N, Singh-Hüsgen $P$, et al. Pentype laser fluorescence device versus bitewing radiographs for caries detection on approximal surfaces. Head Face Med 2016;12:30.

10. Menem R, Barngkgei I, Beiruti N, et al. The diagnostic accuracy of a laser fluorescence device and digital radiography in detecting approximal caries lesions in posterior permanent teeth: an in vivo study. Lasers Med Sci 2017;32:621-8.

11. Shi XQ, Welander U, Angmar-Månsson B. Occlusal caries 
detection with KaVo DIAGNOdent and radiography: an in vitro comparison. Caries Res 2000;34:151-8.

12. Schwendicke F, Göstemeyer G. Conventional bitewing radiography. Clin Dent Rev 2020;4:22.

13. Sato H, Da Silva JD, Lee C, et al. Effects of healthcare policy and education on reading accuracy of bitewing radiographs for interproximal caries. Dentomaxillofac Radiol 2021;50:20200153.

14. Abdinian M, Razavi SM, Faghihian R, et al. Accuracy of Digital Bitewing Radiography versus Different Views of Digital Panoramic Radiography for Detection of Proximal Caries. J Dent (Tehran) 2015;12:290-7.

15. Pitts NB. Are we ready to move from operative to nonoperative/preventive treatment of dental caries in clinical practice? Caries Res 2004;38:294-304.

16. FDI World Dental Federation. FDI policy statement on Minimal Intervention Dentistry (MID) for managing dental caries: Adopted by the General Assembly: September 2016, Poznan, Poland. Int Dent J 2017;67:6-7.

17. Ericson D, Kidd E, McComb D, et al. Minimally Invasive Dentistry--concepts and techniques in cariology. Oral Health Prev Dent 2003;1:59-72.

18. Takahashi N, Lee C, Da Silva JD, et al. A comparison of diagnosis of early stage interproximal caries with bitewing radiographs and periapical images using consensus reference. Dentomaxillofac Radiol 2019;48:20170450.

19. Hopcraft MS, Morgan MV. Comparison of radiographic and clinical diagnosis of approximal and occlusal dental caries in a young adult population. Community Dent Oral Epidemiol 2005;33:212-8.

20. Zaitsu T, Saito T, Kawaguchi Y. The Oral Healthcare System in Japan. Healthcare (Basel) 2018;6:79.

21. White SC, Atchison KA, Hewlett ER, et al. Efficacy of FDA guidelines for prescribing radiographs to detect dental and intraosseous conditions. Oral Surg Oral Med Oral Pathol Oral Radiol Endod 1995;80:108-14.

22. Ministry of Health L, and Welfare. Survey of Medical Care Activities in Public Health Insurance, 20162016 [cited 2021 Mar 11]. Available online: https://www.mhlw. go.jp/english/database/db-hss/smcaphi-2016.html.

23. Schwendicke F, Splieth CH, Bottenberg P, et al. How to intervene in the caries process in adults: proximal and secondary caries? An EFCD-ORCA-DGZ expert Delphi consensus statement. Clin Oral Investig 2020;24:3315-21.

24. Dove SB. Radiographic diagnosis of dental caries. J Dent Educ 2001;65:985-90.

25. Dehghani M, Barzegari R, Tabatabai H, et al. Diagnostic Value of Conventional and Digital Radiography for
Detection of Cavitated and Non-Cavitated Proximal Caries. J Dent (Tehran) 2017;14:21-30.

26. Zero DT, Fontana M, Martínez-Mier EA, et al. The biology, prevention, diagnosis and treatment of dental caries: scientific advances in the United States. J Am Dent Assoc 2009;140 Suppl 1:25S-34S.

27. Goodwin TL, Devlin H, Glenny AM, et al. Guidelines on the timing and frequency of bitewing radiography: a systematic review. Br Dent J 2017;222:519-26.

28. Baghdady MT, Carnahan H, Lam EW, et al. Dental and dental hygiene students' diagnostic accuracy in oral radiology: effect of diagnostic strategy and instructional method. J Dent Educ 2014;78:1279-85.

29. Cury JA, Tenuta LM. Enamel remineralization: controlling the caries disease or treating early caries lesions? Braz Oral Res. 2009;23 Suppl 1:23-30.

30. Rasines Alcaraz MG, Veitz-Keenan A, Sahrmann P, et al. Direct composite resin fillings versus amalgam fillings for permanent or adult posterior teeth. Cochrane Database Syst Rev 2014;(3):CD005620.

31. Ástvaldsdóttir Á, Dagerhamn J, van Dijken JW, et al. Longevity of posterior resin composite restorations in adults - A systematic review. J Dent 2015;43:934-54.

32. Angeletaki F, Gkogkos A, Papazoglou E, et al. Direct versus indirect inlay/onlay composite restorations in posterior teeth. A systematic review and meta-analysis. J Dent 2016;53:12-21.

33. CDC. Oral Health Surveillance Report, 20192019 [cited 2021. Available online: https://www.cdc.gov/oralhealth/ publications/OHSR-2019-index.html.

34. CDC. Health, United States 2019 [cited 2021 Sep 21]. Available online: https://www.cdc.gov/nchs/data/hus/ hus19-508.pdf.

35. Bernabé E, Sheiham A. Age, period and cohort trends in caries of permanent teeth in four developed countries. Am J Public Health 2014;104:e115-21.

36. Ministry of Health L, and Welfare. 2016 Dental disease fact-finding survey conclusion 2016 [cited 2021 Sep 21]. Available online: https://www.mhlw.go.jp/toukei/list/dl/6228-02.pdf.

Cite this article as: Grieco P, Jivraj A, Da Silva J, Kuwajima Y, Ishida Y, Ogawa K, Ohyama H, Ishikawa-Nagai S. Importance of bitewing radiographs for the early detection of interproximal carious lesions and the impact on healthcare expenditure in Japan. Ann Transl Med 2022;10(1):2. doi: 10.21037/atm-21-2197 